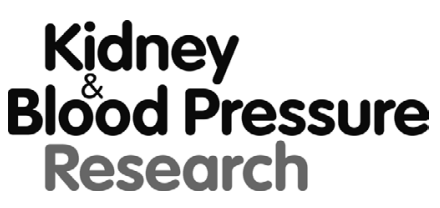

Kidney Blood Press Res 2018;43:664-672

DOI: 10.1159/000489623

Published online: 8 May, 2018

Accepted: 26 April, 2018

This article is licensed under the Creative Commons Attribution-NonCommercial-NoDerivatives 4.0 International License (CC BY-NC-ND) (http://www.karger.com/Services/OpenAccessLicense). Usage and distribution for commercial purposes as well as any distribution of modified material requires written permission.

\title{
Soluble Urokinase Plasminogen Activator Receptor is Associated with Coronary Artery Calcification and Cardiovascular Disease in Patients Undergoing Hemodialysis
}

\author{
Wenjuan Wu Yanhai Cui $^{\mathrm{a}}$ Juan Hua Ruyi Liao ${ }^{\mathrm{a}}$ Sijia Lia Liyi Mo ${ }^{\mathrm{a}}$ Lixia Xua \\ Yuanhan Chen ${ }^{\mathrm{a}}$ Zhiwen Lian ${ }^{\mathrm{a}}$ Xiulan Tian ${ }^{\mathrm{a}}$ Zhuo Lia Ruizhao Lia ${ }^{\mathrm{a}}$ Li Zhang $^{\mathrm{a}}$ \\ Huaban Liang ${ }^{\mathrm{a}}$ Jianchao Ma ${ }^{\mathrm{a}}$ Ting Lin ${ }^{\mathrm{a}}$ Zhonglin Feng ${ }^{\mathrm{a}}$ Wei Donga \\ Guibao Ke ${ }^{a}$ Pingjiang $\mathrm{Ge}^{\mathrm{c}}$ Zhiming Ye ${ }^{\mathrm{a}}$ Wenjiang Wang ${ }^{\mathrm{a}}$ Bing Zhang ${ }^{\mathrm{a}}$ \\ Wei Shi ${ }^{a} \quad$ Xinling Liang ${ }^{a}$ Shuangxin Liu ${ }^{a}$ \\ aDepartment of Nephrology, Guangdong General Hospital, Guangdong Academy of Medical Sciences, \\ Guangdong Geriatrics Institute, Guangzhou, 'Department of Radiology, Guangdong General Hospital, \\ Guangdong Academy of Medical Science, Guangzhou, 'Department of Otolaryngology, Guangdong \\ General Hospital, Guangdong Academy of Medical Science, Guangzhou, China
}

\section{Key Words}

Hemodialysis • SuPAR • Vascular calcification • Cardiovascular diseases

\begin{abstract}
Background/Aims: Cardiovascular disease (CVD) is an important cause of morbidity and mortality in hemodialysis patients. Vascular calcification is thought to play an important role in causing CVD. Soluble urokinase plasminogen activator receptor (suPAR) is a biomarker strongly predictive of cardiovascular outcomes in the pathogenesis of diabetic patients with renal disease treated with hemodialysis. We investigated the relationship between SUPAR and coronary artery calcification (CAC) in patients undergoing maintenance hemodialysis. Methods: A total of 99 adult hemodialysis patients were enrolled in this study. Plasma samples were analyzed for suPAR with an enzyme-linked immunosorbent assay and the CAC score was determined with multidetector computed tomography. The occurrence of cardiovascular events and all-cause mortality during follow-up were recorded from January 1, 2010 to June 1, 2016. Results: In 99 patients treated with maintenance hemodialysis, 91 (91.9\%) had varying degrees of CAC, and suPAR correlated positively with the CAC score in a Spearman analysis. In a mean follow-up period of 33 months, 36 patients (36.4\%) experienced at least
\end{abstract}

W. Wu, Y. Cui and J. Hu contributed equally to this work.

Xinling Liang

and Shuangxin Liu
Department of Nephrology, Guangdong General Hospital

Zhongshan Er Lu 106, Guangzhou City, Guangdong (China)

E-Mail xinlingliang_ggh@139.com; 13543456446@139.com 


\section{Kidney Blood Pressure Research}

Kidney Blood Press Res 2018;43:664-672

\begin{tabular}{l|l}
\hline DOI: $10.1159 / 000489623$ & (C) 2018 The Author(s). Published by S. Karger AG, Basel
\end{tabular}

Published online: 8 May, 2018

www.karger.com/kbr

one cardiovascular event. When the quartiles of suPAR concentrations were used as the cutoff points for a subgroup analysis, the incidence of CVD and all-cause mortality was much higher in the higher quartiles of suPAR. In a univariate Cox regression analysis, high suPAR was a risk factor for CVD and all-cause mortality. Conclusion: suPAR is associated with the CAC score and is a risk factor for new-onset CVD in patients undergoing hemodialysis.

\section{Introduction}

Chronic kidney disease (CKD) is a growing public health problem, affecting over $10 \%$ of the world's population [1]. At least 2 million patients are receiving dialysis for end-stage renal disease (ESRD) throughout the world [2]. Despite advances in dialysis technology, the morbidity and mortality of dialysis patients has not improved much and is unacceptably high. Cardiovascular disease (CVD)-related morbidity and mortality in ESRD patients undergoing hemodialysis is 10-30-fold higher than in the general population. Vascular calcification is an important cause of morbidity and mortality in hemodialysis patients.

Soluble urokinase plasminogen activator receptor (suPAR), a new inflammatory biomarker, is produced during the inflammatory response. When the urokinase plasminogen activator receptor (UPAR) is cleaved from the cell membranes of endothelial cells and macrophages, it becomes a soluble factor [3]. Previous studies have shown that suPAR is associated with the coronary artery calcification (CAC) score (CACS) independently of the systematic coronary risk, and provides prognostic information on the CVD risk in the general population [4-7]. suPAR is also a biomarker strongly predictive of cardiovascular outcome in the pathogenesis of diabetic renal disease patients treated with hemodialysis [8-9]. However, it is unclear whether suPAR levels are associated with CAC in patients undergoing hemodialysis. Therefore, we investigated the relationship between suPAR CAC, and CVD in patients treated with maintenance hemodialysis.

\section{Materials and Methods}

\section{Study design}

This was a prospective study carried out between January 2010 and June 2016 at the Nephrology Department of the Guangdong General Hospital (Guangdong, China). All experiments were approved by the Ethical Committee of Guangdong General Hospital (GDREC 2010201H). The study subjects were informed of the purpose and nature of the study and gave their written informed consent to their participation.

Ninety-nine adult patients (18-75 years), consisting of 53 males and 46 females, who had been treated with ongoing hemodialysis for at least 6 months at Guangdong General Hospital, were enrolled in the study and invited to undergo an multidetector computed tomography scan. Patients with an active infection (highsensitivity C-reactive protein [hs-CRP] $>12 \mathrm{mg} / \mathrm{L}$ ) were excluded. Among the remaining study subjects, 63 had glomerulonephritis, 14 had diabetic nephropathy, 12 had hypertensive nephropathy, 4 had polycystic kidney, 2 had renal artery stenosis, 2 had obstructive nephropathy, 1 had malignant renal tumor, and 1 had an unknown etiology. The median age was $52.0 \pm 14.3$ years and the median period of dialysis was 72.5 \pm 58.6 months. All the patients underwent routine hemodialysis with a $4 \mathrm{~h}$ dialysis session three times a week, with standard high-flux dialysis membranes. The dialysate contained the following concentrations: Na 135-140 mmol/L, K 2.0-3.0 mmol/L, Ca 1.25-1.5 mmol/L, and bicarbonate $25.0 \mathrm{mmol} / \mathrm{L}$. The patients were evaluated for dialysis adequacy every 3 months and spKt/V was $>1.2$ in all patients.

\section{Biochemical analyses}

Blood was drawn before dialysis at the time of the regular dialysis treatment. Blood levels of suPAR were measured in frozen EDTA-plasma samples stored at $-80{ }^{\circ} \mathrm{C}$. The samples were analyzed with the human uPAR Quantikine® ELISA Kit (R\&D Systems, Minneapolis, MN), according to the instructions of the manufacturer. 


\section{Kidney Blood Pressure Research}

Kidney Blood Press Res 2018;43:664-672

\begin{tabular}{l|l}
\hline DOI: $10.1159 / 000489623$ & (C) 2018 The Author(s). Published by S. Karger AG, Basel
\end{tabular}

Published online: 8 May, 2018 www.karger.com/kb

Serum calcium, phosphorus, albumin (Alb), hemoglobin (Hb), alkaline phosphatase (ALP), hs-CRP, and intact parathyroid hormone (iPTH) were measured with standard procedures at the Department of Laboratory at Guangdong General Hospital.

CAC

CACS was determined with a noncontrast cardiac computed tomography scan performed during an inspiratory breath hold, by an experienced cardiologist. To assess CAC, the Radiology Department used a GE 64-slice CT scanner (GE LightSpeed VCT, Massachusetts) with the following technical settings: gantry rotation time $500 \mathrm{~ms}, 2.5 \mathrm{~mm}$ collimation, $120 \mathrm{kV}$ tube voltage, $200 \mathrm{~mA}$ tube current, and prospectively electrocardiography -triggered scan acquisition gating at $50 \%$ of the R-R interval.

The CACS was calculated by adding the scores from all the foci in the coronary arteries, and is given in Agatston units (U) [10]. To make it more manageable in the clinical setting, CACs was divided into five categories: 0, 1-9, 10-99, 100-399, > $400 \mathrm{U}$, corresponding to none, very low, low, moderate, and severe coronary calcification [11]. A cut-off value of $100 \mathrm{U}$, which is generally accepted as corresponding to significant coronary calcification, was chosen for the final analysis [12].

\section{Recording CVD events and mortality}

Patients were followed-up prospectively at our dialysis center until June 1,2016. If the patient was referred for peritoneal dialysis or kidney transplantation, they were deemed to be lost to follow-up, starting from the date of the last actual visit. The cardiovascular end-points were recorded based on clinical and biochemical data. The primary end-points were overall mortality and the time to the first cardiovascular event. The latter was a composite of death from cardiac causes, nonlethal myocardial infarction (MI), myocardial ischemia, coronary intervention, and ischemic stroke (ICD-10) [13], whichever occurred first. Only one event per subject was included in the analysis.

\section{Statistical analyses}

Data are expressed as means (standard deviations) for normally distributed variables or medians with the $25^{\text {th }}$ and $75^{\text {th }}$ percentiles for nonnormally distributed variables. The normally distributed continuous variables were compared with Student's $t$ test, whereas the nonnormally distributed continuous variables were analyzed with the nonparametric Mann-Whitney $U$ test. Categorical variables are presented as frequencies and the corresponding percentages, and a $\chi^{2}$ test or Fisher's exact test was used to compare them, as appropriate. Variables with a nonnormal distribution were log-transformed using the natural logarithm. The correlations between the levels of suPAR and other variables were calculated with Spearman's rank correlation coefficients. The cumulative incidence of end-point events was calculated with the Kaplan-Meier method. The time to mortality and the time to the first cardiovascular event were analyzed with the Cox proportional hazards model. The results are expressed as ratios of the expected geometric means between groups, with their $95 \%$ confidence intervals. Two-sided $\mathrm{P}<0.05$ was considered statistically significant. All statistical analyses were performed with SPSS 23.0.

\section{Results}

\section{Patient characteristics}

The study sample comprised 99 subjects, of whom 53 were men and 46 women. The patients were divided two groups according to their cardiovascular events (Table 1). Compared with the no-CVD group, the CVD group had higher CACS, higher hs-CRP levels, and had experienced longer periods of dialysis. Plasma suPAR levels were significantly higher in the CVD group than in the no-CVD group $(\mathrm{P}=0.043)$. There were no significant differences between the CVD group and no-CVD group in the parameters age, sex, serum calcium, phosphorus, iPTH, $\mathrm{Hb}$ and Alb. 


\section{Kidney \\ Blood Pressure Research}

Kidney Blood Press Res 2018;43:664-672

\begin{tabular}{l|l}
\hline DOI: $10.1159 / 000489623$ & (C) 2018 The Author(s). Published by S. Karger AG, Basel
\end{tabular}

Published online: 8 May, 2018 www.karger.com $/ \mathrm{kb}$

Hemodialysis

Table 1. Comparison of patient characteristics in the CVD and no-CVD groups. Abbreviations: iPTH, intact parathyroid hormone; hs-CRP, high-sensitivity C-reactive protein; CAC, coronary artery calcification; CVD, cardiovascular disease; suPAR, soluble urokinase plasminogen activator receptor. Data are means $\pm \mathrm{SD}$, medians (25-75 percentiles), or numbers (\%) P values are reported for differences between the CVD group and no-CVD group

\begin{tabular}{|c|c|c|c|}
\hline Characteristics & $\begin{array}{l}\text { No CVD } \\
(n=63)\end{array}$ & $\begin{array}{c}\text { CVD } \\
(n=36)\end{array}$ & $\mathrm{P}$ \\
\hline Age (year) & $50.0 \pm 14.3$ & $55.4 \pm 14.0$ & 0.074 \\
\hline Male $(n, \%)$ & $34(54 \%)$ & $19(52.8 \%)$ & 0.91 \\
\hline Time on hemodialysis (month) & $60(34,72)$ & $74(48,117)$ & 0.009 \\
\hline Calcium(mmol/L) & $2.3 \pm 0.2$ & $2.3 \pm 0.4$ & 0.584 \\
\hline Phosphorous(mmol/L) & $2.0 \pm 0.7$ & $1.8 \pm 0.9$ & 0.380 \\
\hline iPTH(pg/mL) & $314(178,1003)$ & $413(119,1586)$ & 0.670 \\
\hline Hemoglobin (g/L) & $105 \pm 20.0$ & $106.8 \pm 21.4$ & 0.678 \\
\hline Albumin $(\mathrm{g} / \mathrm{L})$ & $33.9 \pm 4.1$ & $32.8 \pm 5.1$ & 0.211 \\
\hline Alkaline phosphatase $(\mathrm{U} / \mathrm{L})$ & $153.8 \pm 236.4$ & $199.5 \pm 218$ & 0.344 \\
\hline hs-CRP(mg/L) & $2.9(1.9,4.2)$ & $3.8(2.7,4.9)$ & 0.021 \\
\hline CACS(score) & $71.5(17.8,190.4)$ & $910(308,1403)$ & $<0.001$ \\
\hline $\operatorname{suPAR}(\mathrm{pg} / \mathrm{mL})$ & $3449(864,6533)$ & $5803(2948,7666)$ & 0.043 \\
\hline Hypertension (n,\%) & $51(81 \%)$ & $31(86.1 \%)$ & 0.518 \\
\hline Diabetes mellitus (n,\%) & $8(12.7 \%)$ & $8(22.2 \%)$ & 0.220 \\
\hline
\end{tabular}

Comparison of sUPAR in diabetic and nondiabetic patients treated with maintenance hemodialysis

Among the patients treated with maintenance hemodialysis, 16 had diabetes and 83 were not diabetic. Although suPAR was higher in the diabetic group than in the nondiabetic group, the difference was not significant (Fig. 1).

\section{Relationship between CACS and sUPAR}

When the relationship between CACS and suPAR was examined with a

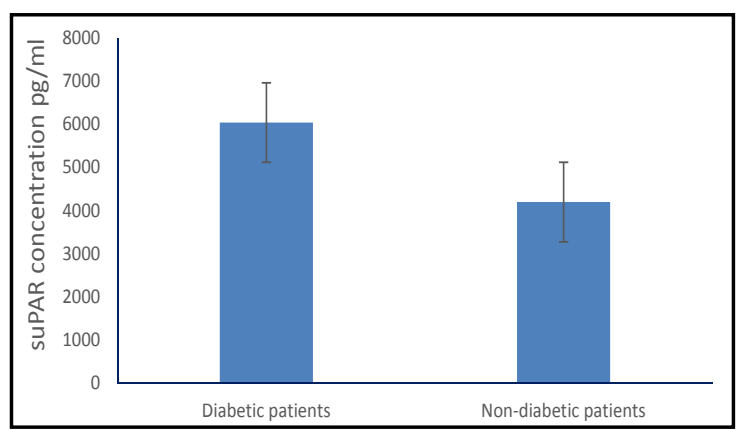

Fig. 1. Comparison of suPAR in diabetic and nondiabetic patients undergoing maintenance hemodialysis. Spearman rank analysis, the two variables were found to be positively associated $(\mathrm{r}$ $=0.315, \mathrm{P}=0.001$ ) (Fig. 2). Furthermore, when CACS was divided into two groups, CACS < 100 and CACS $\geq 100$, the suPAR plasma levels were significantly higher in the CACS $\geq 100$ group $(4808[2350,7267] \mathrm{pg} / \mathrm{mL})$ than in the CACS $<100$ group $(2742[644,6572] \mathrm{pg} / \mathrm{mL}$; $\mathrm{P}=0.048)$.

\section{SUPAR and CVD}

We analyzed the association between suPAR and CVD in patients undergoing maintenance dialysis, with a mean follow-up period of 33 months. During the study period, 36 of the 99 patients $(36.4 \%)$ experienced at least one cardiovascular event. The quartiles of the suPAR levels were used as the cut-off points for the subgroup analysis, and a clear association was observed between higher suPAR and new-onset CVD in these patients (Table 2). In a univariate Cox regression analysis, high suPAR was a risk factor for CVD (hazard ratio $[\mathrm{HR}]=2.573$ [1.708-3.876], $\mathrm{P}<0.001$ ).

In the univariate Cox analysis, high suPAR was directly associated with cardiovascular events, as were greater age, longer period of dialysis, higher CRP, CACS, and ALP (Table 3). In the COX proportional hazards model after adjustment for multiple factors, suPAR remained an independent risk factor for CVD (HR $=2.960$ [1.638-5.355], $\mathrm{P}<0.001)$. In a multivariate 


\section{Kidney Blood Pressure Research}

Fig. 2. Correlation between suPAR and CACS. A significant positive correlation was detected between CACS and suPAR $(\mathrm{r}=0.315, \mathrm{P}$ $=0.001)$.

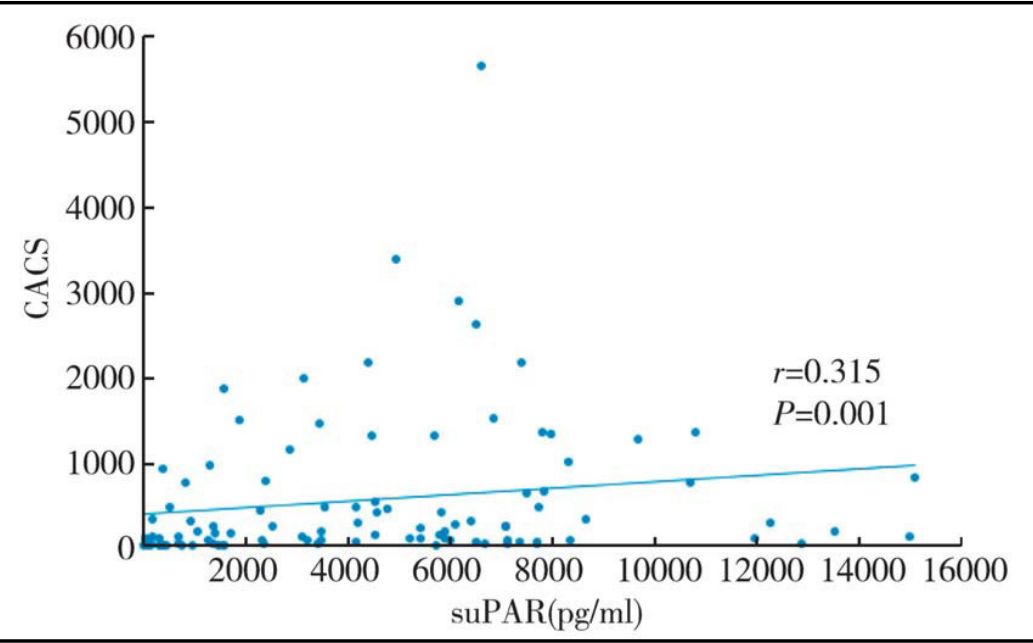

Cox analysis, suPAR was independently associated with cardiovascular events after adjustments were made for multiple factors (HR = 3.629 [1.823-7.225], $\mathrm{P}<0.001)$.

In the univariate Cox regression analysis, high suPAR was a risk factor for mortality (HR $=2.806$ [1.139-6.915], $\mathrm{P}=0.025)$. In the Cox proportional hazards model after adjustment for multiple factors, suPAR was no longer an independent factor for mortality (HR $=2.401$ [0.666-8.66], $\mathrm{P}=0.181$ ) (Table 4).
Table 2. Comparison of new-onset CVD and death in each quartile of suPAR

\begin{tabular}{lcc}
\hline Variable & CVD (n, \%) & Death (n, \%) \\
\hline Quartile 1 & $4(16 \%)$ & $1(4 \%)$ \\
Quartile 2 & $9(37.5 \%)$ & $2(8.3 \%)$ \\
Quartile 3 & $10(41.7 \%)$ & $2(8.3 \%)$ \\
Quartile 4 & $13(50 \%)$ & $5(19.2 \%)$ \\
P & $<0.001$ & 0.001 \\
\hline
\end{tabular}

\section{sUPAR and mortality}

We investigated the link between suPAR and overall mortality. During the study period, $10(10.1 \%)$ patients died, eight (80\%) from cardiovascular death, and the other two from systemic failure attributable to infection secondary to CVD. A definite association was observed between high suPAR and mortality in patients treated with maintenance hemodialysis $(\mathrm{P}=$ 0.001). A Kaplan-Meier analysis showed clear differences in the rate of CVD occurrence in the four groups (log rank 32.482, $\mathrm{P}<0.001$ ). The survival curves for the quartiles of suPAR demonstrated a specific association between suPAR and overall mortality $(P=0.001)$ (Fig. 3). In a univariate Cox analysis, high suPAR was directly associated with mortality, as were greater age, CACS, longer period of dialysis, and diabetes. We used a Spearman rank analysis to assess the risk factors for suPAR, but found known positive association with age, female sex, period of dialysis, serum phosphorus, ALP, or hs-CRP (all P < 0.05) (Table 5).

\section{Discussion}

The mortality risk for patients with ESRD is substantially greater than that for the general population. The higher CVD rate is due, in part, to traditional risk factors in the general population, such as old age, hypertension, diabetes, and dyslipidemia [14]. However, typical cardiovascular risk factors are insufficient to accurately predict the cardiovascular risk in patients with CKD and vascular calcification is one of the principal contributors to CVD in ESRD. Several studies have demonstrated that CACS is associated with CVD and mortality in patients with CKD undergoing dialysis [15-18]. Our study has also shown that CACS is independently associated with CVD and all-cause mortality in patients treated with hemodialysis. 


\section{Kidney Blood Pressure Research}

Table 3. Cox proportional hazard analysis of the time to the first cardiovascular event. Abbreviations: suPAR, soluble urokinase plasminogen activator receptor; CACS, coronary artery calcification score; ALP, alkaline phosphatase; hs-CRP, high sensitivity $\mathrm{C}$-reactive protein; $\mathrm{Hb}$, hemoglobin; $\mathrm{iPTH}$, intact parathyroid hormone; CVD, cardiovascular disease

\begin{tabular}{lc}
\hline Variable & Hazard ratio(95\%CI) \\
\hline 1.Unadjusted suPAR(Ln) & $2.573(1.708-3.876)$ \\
2.CACS(Ln) & $2.082(1.574-2.752)$ \\
3.CACS(Ln), age dialysis vintage, Alp, hs-CRP(Ln) & $2.960(1.638-5.355)$ \\
4.Full model: age, gender, dialysis vintage, calcium, phosphorus, Hb, albumin, ALP, & $3.629(1.823-7.225)$ \\
iPTH(Ln), CACS(Ln), hsCRP(Ln), diabetes, hypertension, prior CVD & $<0.001$
\end{tabular}

Table 4. Cox proportional hazard survival analysis. Abbreviations: suPAR, soluble urokinase plasminogen activator receptor; CACS, coronary artery calcification score; ALP, alkaline phosphatase; hs-CRP, highsensitivity C-reactive protein; Hb, hemoglobin; iPTH, intact parathyroid hormone; CVD, cardiovascular disease

\begin{tabular}{lcc}
\hline Variable & Hazard ratio(95\%CI) & P \\
\hline 1.Unadjusted suPAR (Ln) & $2.806(1.139-6.915)$ & 0.025 \\
2.CACS(Ln) & $1.904(1.169-3.10)$ & 0.01 \\
3.CACS(Ln),age, diabetes & $2.411(0.917-6.495)$ \\
4. Full model: age, gender, dialysis vintage, calcium, phosphorus, Hb, albumin, & 0.07 \\
Alp, iPTH(Ln),CACS(Ln), hsCRP(Ln),diabetes, hypertension, prior CVD & $2.401(0.666-8.66)$ \\
\hline
\end{tabular}

Fig. 3. Event-free cardiovascular disease and survival stratified by suPAR quartiles. Kaplan-Meier curves of the time to a cardiovascular event and the number of surviving patients as a function of suPAR concentration quartiles. The survival curves for the quartiles of suPAR show a specific association between

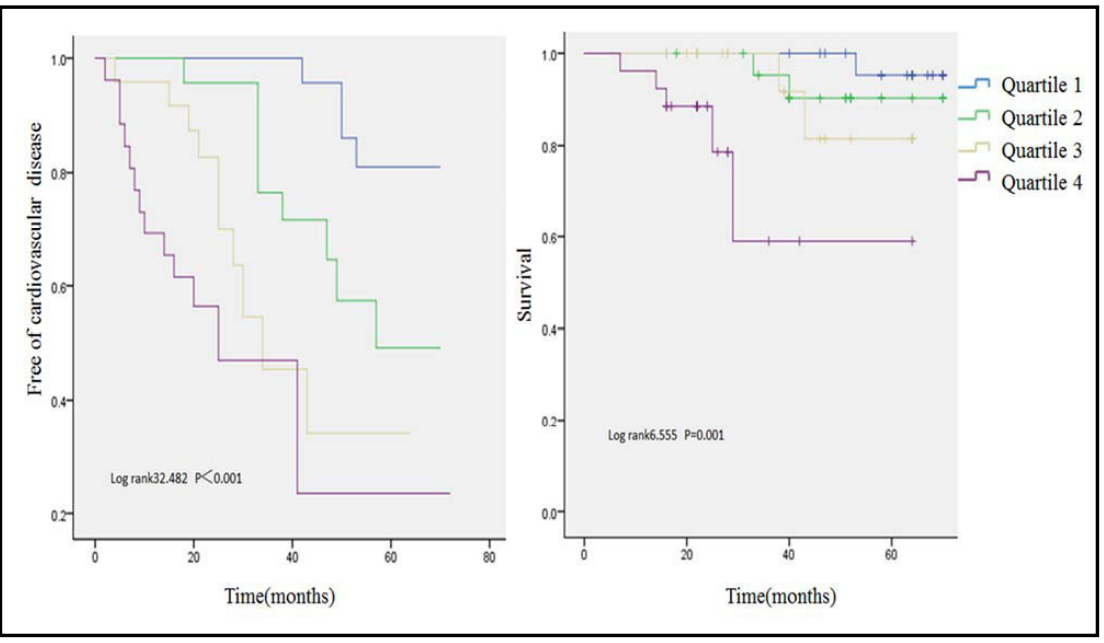
SUPAR (log rank 32.482, $\mathrm{P}<0.001$ ) and overall mortality (log rank 6.555, $\mathrm{P}=0.001)$.

suPAR originates from the proteolytic cleavage of UPAR. suPAR is composed of three domains (D1-D3) and arises from cleavage of uPAR at the glycosylphosphatidylinositol anchor. suPAR is found in the serum, plasma, and other body fluids, and because its mass is $\sim 56 \mathrm{kDa}$, it is not usually eliminated by ordinary dialyzers [19]. Previous studies have found higher suPAR concentrations in older patients ( $>50$ years) and female patients, which is consistent with our results. We also found that suPAR was positively associated with the period of dialysis and iPTH, phosphorous, and ALP levels, suggesting that suPAR probably provides prognostic information on the CKD population.

As well as CKD-specific abnormalities, such as anemia, disturbances of the bone and mineral metabolism, and the retention of organic solutes, it has become increasingly clear that chronic inflammation plays a vital role in the development of atherosclerosis and CVD, 


\section{Kidney Blood Pressure Research}

Kidney Blood Press Res 2018;43:664-672

DOI: 10.1159/000489623

Published online: 8 May, 2018 (c) 2018 The Author(s). Published by S. Karger AG, Basel www.karger.com $/ \mathrm{kbr}$

Wu et al.: SuPAR is Associated with Coronary Artery Calcification in Patients with

Hemodialysis especially in ESRD [20]. suPAR, an emerging inflammatory biomarker, seems to be linked to endothelial dysfunction and the presence of atherosclerotic plaques, and therefore potentially reflects the later processes that occur in the development of CVD. Lynqbaek et al. [21] demonstrated that suPAR behaves differently from CRP and outperforms CRP in predicting CVD. Therefore, the combination of both factors should significantly improve the prognostic information on CVD risk. suPAR is also a novel indicator of risk in the CKD population. A recent large study involving 3683 patients demonstrated that elevated suPAR levels were independently associated with the incidence of CKD and predicted an accelerated decline in the estimated glomerular filtration rate in groups [22].

suPAR is also associated with the development, severity, and outcome of coronary artery disease. In a study that analyzed 296 patients with ST-elevation MI undergoing a primary percutaneous coronary intervention, suPAR remained associated with mortality and the risk of MI recurrence during the 5.76-year follow-up period [21]. Another study [23] that followed 1126 healthy middle-aged people for a 10 -year period suggested that suPAR is associated with CACS independently of the evaluated systematic coronary risk, and provides prognostic information on CVD risk in the general population beyond the Framingham risk score. suPAR levels also reflect low-grade inflammation and are associated with lifestyle factors such as smoking, alcohol intake, and sedentary lifestyle. suPAR levels are also higher in women than in men. We found that suPAR is an independent risk factor for CVD in both univariate and multivariate Cox analyses. suPAR may also be a marker of established CVD. After adjustment for a past history of CVD, suPAR remained an independent determinant of cardiovascular events.

One limitation of this study is that we were unable to provide a definite mechanistic explanation for the observed strong association between suPAR and cardiovascular events. Several plausible mechanisms may explain our findings, including chronic inflammation and/or the overproduction of suPAR by the diseased vasculature. Although suPAR is associated with several aspects of CVD, we do not know whether suPAR plays a causal role in cardiovascular pathogenesis or merely reflects the disease process. Our study sample size was small and the follow-up period short, so additional studies with greater numbers of patients and long-term follow-up are required. However, our group is the first to establish an association between suPAR and cardiovascular morbidity and mortality in patients undergoing maintenance dialysis.

\section{Conclusion}

suPAR is associated with CACS and shows a clear, positive association with the risk of new-onset CVD in patients undergoing maintenance dialysis.

\section{Acknowledgements}

We thank nurse (Hemodialysis Purification Center, Guangdong General Hospital, Guangdong Academy of Medical Sciences) for his work in collecting samples. This work was supported by Guangdong Provincial Science and Technology Foundation (No. 


\section{Kidney \\ Blood Pressure Research}

Kidney Blood Press Res 2018;43:664-672

\begin{tabular}{l|l}
\hline DOI: $10.1159 / 000489623$ & (C) 2018 The Author(s). Published by S. Karger AG, Basel
\end{tabular}

Published online: 8 May, 2018 www.karger.com/kb

Hemodialysis

2014A030313544), the National Natural Science Foundation (No. 81670656, 81270784 and 81170683), Guangzhou City Science and Technology Project (No. 12A56041537, 2012J4300084 and 201707010009), National Key Technology R\&D Program (No. 2011BAI10B06), National key clinical specialist construction Programs of China, and Medical Scientific Research Foundation of Guangdong Province General Hospital.

\section{Disclosure Statement}

The authors declare no conflict of interest regarding the publication of this article.

\section{References}

1 Jha V, Garcia-Garcia G, Iseki K: Chronic kidney disease: global dimension and perspectives. Lancet 2013;382:260-272.

-2 Woo KT, Choong HL, Wong KS, Tan HB, Chan CM: The contribution of chronic kidney disease to the global burden of major noncommunicable diseases. Kidney Int 2012;81:1044-1045.

- Montuori N, Selleri C, Ragno P: The urokinase-receptor in infectious diseases. Infez Med 2012;20:13-18.

4 Persson M, Engström G, Björkbacka H, Hedblad B: Soluble urokinase plasminogen activator receptor in plasma is associated with incidence of CVD. Results from the Malmö Diet and Cancer Study. Atherosclerosis 2012;220:502-505.

-5 Eugen-Olsen J, Andersen O, Linneberg A, Ladelund S, Hansen TW, Langkilde A, Petersen J, Pielak T, Møller LN, Jeppesen J, Lyngbaek S, Fenger M, Olsen MH, Hildebrandt PR, Borch-Johnsen K, Jørgensen T, Haugaard SB: Circulating soluble urokinase plasminogen activator receptor predicts cancer, cardiovascular disease, diabetes and mortality in the general population. J Intern Med 2010;268:296-308.

-6 Harskamp RE, Roe MT: Soluble urokinase-type plasminogen activator receptor: a useful biomarker for coronary artery disease and clinical outcomes? J Am Heart Assoc 2014;3:e001431.

-7 Eapen DJ, Manocha P, Ghasemzadeh N, Patel RS, Al Kassem H, Hammadah M, Veledar E, Le NA, Pielak T, Thorball CW, Velegraki A, Kremastinos DT, Lerakis S, Sperling L, Quyyumi AA: Soluble urokinase plasminogen activator receptor level is an independent predictor of the presence and severity of coronary artery disease and of future adverse events. J Am Heart Assoc 2014;3:e001118.

-8 Drechsler C, Hayek SS, Wei C, Sever S, Genser B, Krane V, Meinitzer A, März W, Wanner C, Reiser J: Soluble Urokinase plasminogen activator receptor and outcomes in patients with diabetes on hemodialysis. Clin J Am Soc Nephrol 2017;12:1265-1273.

-9 Wlazeł RN, Szadkowska I, Bartnicki P, Rośniak-Bąk K, Rysz J: Clinical and prognostic usefulness of soluble urokinase plasminogen activator receptor in hemodialysis patients. Int Urol Nephrol 2018; DOI:10.1007/s11255-017-1778-5.

10 Rumberger JA, Simons DB, Fitzpatrick LA, Sheedy PF, Schwartz RS: Coronary artery calcium area by electron-beam computed tomography and coronary atherosclerotic plaque area. A histopathologic correlative study. Circulation 1995;92:2157-2162.

11 Diederichsen AC, Petersen H, Jensen LO, Thayssen P, Gerke O, Sandgaard NC, Høilund-Carlsen PF, Mickley $\mathrm{H}$ : Diagnostic value of cardiac 64-slice computed tomography: importance of coronary calcium. Scand Cardiovasc J 2009;43:337-344.

12 Polonsky TS, McClelland RL, Jorgensen NW, Bild DE, Burke GL, Guerci AD, Greenland P: Coronary artery calcium score and risk classification for coronary heart disease prediction. JAMA 2010;303:1610-1616.

13 International Classification of Diseases (ICD). Version:2016. http://apps.who.int/classifications/icd10/ browse/2016/en.

14 Erbel R, Möhlenkamp S, Moebus S, Schmermund A, Lehmann N, Stang A, Dragano N, Grönemeyer D, Seibel R, Kälsch H, Bröcker-Preuss M, Mann K, Siegrist J, Jöckel KH, Heinz Nixdorf Recall Study Investigative Group: Coronary risk stratification, discrimination, and reclassification improvement based on quantification of subclinical coronary atherosclerosis: the Heinz Nixdorf Recall study. J Am Coll Cardiol 2010;56:1397-1406. 


\section{Kidney \\ Blood Pressure Research}

Kidney Blood Press Res 2018;43:664-672

DOI: $10.1159 / 000489623$

Published online: 8 May, 2018

(C) 2018 The Author(s). Published by S. Karger AG, Base www.karger.com/kbr

Wu et al.: SuPAR is Associated with Coronary Artery Calcification in Patients with

Hemodialysis

15 Raggi P, Gongora MC, Gopal A, Callister TQ, Budoff M, Shaw LJ: Coronary artery calcium to predict all-cause mortality in elderly men and women. J Am Coll Cardiol 2008;52:17-23.

-16 Claes KJ, Heye S, Nuyens D, Bammens B, Kuypers DR, Vanrenterghem Y, Evenepoel P: Impact of vascular calcification on corrected QT interval at the time of renal transplantation. Am J Nephrol 2012;35:24-30.

17 Block GA, Raggi P, Bellasi A, Kooienga L, Spiegel DM: Mortality effect of coronary calcification and phosphate binder choice in incident hemodialysis patients. Kidney Int 2007;71:438-441.

18 Sarnak MJ, Levey AS, Schoolwerth AC, Coresh J, Culleton B, Hamm LL, McCullough PA, Kasiske BL, Kelepouris E, Klag MJ, Parfrey P, Pfeffer M, Raij L, Spinosa DJ, Wilson PW: Kidney disease as a risk factor for development of cardiovascular disease: a statement from the American Heart Association Councils on Kidney in Cardiovascular Disease, High Blood Pressure Research, Clinical Cardiology, and Epidemiology and Prevention. Circulation 2003;108:2154-2169.

19 Thuno M, Macho B, Eugen-Olsen J: suPAR: the molecular crystal ball. Dis Markers 2009;27:157-172.

-20 Stinghen AE, Bucharles S, Riella MC, Pecoits-Filho R: Immune mechanisms involved in cardiovascular complications of chronic kidney disease. Blood Purif 2010;29:114-120.

-21 Lyngbæk S, Marott JL, Møller DV, Christiansen M, Iversen KK, Clemmensen PM, Eugen-Olsen J, Jeppesen JL, Hansen PR: Usefulness of soluble urokinase plasminogen activator receptor to predict repeat myocardial infarction and mortality in patients with ST-segment elevation myocardial infarction undergoing primary percutaneous intervention. Am J Cardiol 2012;110:1756- 1763.

22 Hayek SS, Sever S, Ko YA, Trachtman H, Awad M, Wadhwani S, Altintas MM, Wei C, Hotton AL, French AL, Sperling LS, Lerakis S, Quyyumi AA, Reiser J: Soluble urokinase receptor and chronic kidney disease. N Engl J Med 2015;373:1916-1925.

-23 Sørensen MH, Gerke O,Eugen-Olsen J, Munkholm H, Lambrechtsen J, Sand NP, Mickley H, Rasmussen LM, Olsen MH, Diederichsen A: Soluble urokinase plasminogen activator receptor is in contrast to highsensitive C-reactive-protein associated with coronary artery calcifications in healthy middle-aged subjects. Atherosclerosis 2014;237:60-66. 